\title{
SEXUALLY TRANSMITTED DISEASES IN MWANZA, TANZANIA: RISK, BELIEFS, HEALTH CARE SEEKING BEHAVIOUR, AND RESPONSES.
}

\author{
George K Lwihula ${ }^{1}$, Anne Outwater ${ }^{2}$ and Klinton Nyamuryekung' $\mathrm{e}^{3}$
}

\begin{abstract}
Objective: In Mwanza region, an HIV/STD intervention program has been in progress in the rural population since 1991 . The information in this study was gathered to increase understanding about lay concepts of sexually transmitted diseases and to provide information to inform HIV/AIDS/STD interventions.

Methods: During a rapid ethnographic survey, 4 investigators conducted more than 100 interviews in 3 rural villages and one roadside settlement with a wide range of key informants including fishers, truck drivers, professional sex workers, STD patients, traditional healers, health care workers, bar attendants, and traders.

Results: High-risk transmission sites included bars, guesthouses, periodic markets, and beaches. People at high risk included men with money and/or away from home such as truck drivers, fishers, government officials, and businessmen, and single women who are barmaids, traders, and secondary school students. Despite linguistic differences in typologies, signs and symptoms were similar in many reported STD conditions when compared to the biomedical model. Some common conditions and diseases e.g. schistosomiasis were believed incorrectly to be sexually transmitted. Multiple sources of treatment were sought. Conclusion: The existence of transient social groups with high-risk behaviour is a challenge to the organization and delivery of STD services. Effective interventions will entail cooperation between multiple sectors based on detailed knowledge of local populations and conditions. Interventions should be accompanied by simple research techniques to assist timely assessment.
\end{abstract}

Key words: Tanzania, East Africa, HIV/AIDS, STDs, health beliefs, migration, fishermen, sex workers, schistosomiasis, STD typology

\section{Introduction}

Lake Victoria stretches between Kenya, Tanzania, and Uganda and has been settled for millennia. The groups of people living there each inhabited and utilized separate ecological niches. Fisher people lived along the shores, and nomadic herders and sedentary farmers enmeshed in a symbiotic banana-cattle agriculture system lived further inland (1). The majority of the people in Mwanza region still live in rural areas and these patterns persist.

However during the mid 1990's, a time of national growth, Mwanza was a regional hub in the expansion of the fish processing, mining and brewing industries. The national and regional setting has been well described (2). Life expectancy was 46 years for women and 50 years for men.

People are mobile. In a regional survey, $7 \%$ of men and $16 \%$ of women reported that they had immigrated into the study communities during the previous two years. More than $40 \%$ of men and about $30 \%$ of women reported having travelled outside their district of residence at least once during the past 12 months (2).

In Mwanza region, an HIV/STD intervention program has been in progress in the rural population since 1991 (3-4). This trial was conducted by AMREF Mwanza in collaboration with the Government of Tanzania, National Institute for Medical Research (NIMR), and Bugando Medical Centre (BMC) $(2,5,6)$. One of the major findings of the larger study was that improved STD services lead to a significant reduction in HIV incidence at the population level (7).

\footnotetext{
Corresponding author: Anne Outwater, Box 105211, Dar es Salaam, Tanzania. Email:anneoutwater@yahoo.com

${ }^{1}$ The late professor and Head of the Department of Behavioural Sciences, School of Public Health and Social Sciences, Muhimbili University College of Health Sciences, Dar es Salaam, ${ }^{2}$ PhD candidate at Johns Hopkins University School of Nursing, Baltimore, MD. USA. ${ }^{3}$ Surgeon at Kagera Regional Hospital, Tanzania
}

It had been found that most men and women in Mwanza are in a stable marital union - $96.7 \%$ of couples were concordant-negative; $0.9 \%$ concordant-positive; $1.2 \%$ were discordant with the male partner being HIV-positive and $1.2 \%$ were discordant with the female partner being HIVpositive (6). Thirty six percent of men and $33 \%$ of women had been widowed or divorced at least once (2). Casual sex during the past year was reported by $53 \%$ of men and $15 \%$ of women in rural Mwanza, but only $2 \%$ of men reported sexual contact with bargirls or commercial sex workers (5). Nearly all extramarital partnerships (96\%), reported by men involved unmarried women (8). In the rural communities the prevalence of HIV infection was $3.4 \%$ in men and $4.2 \%$ in women as compared to $7.5 \%$ and $7.9 \%$ at the roadside communities (2). Active serological syphilis was $7.8 \%$ in men and $9.1 \%$ in women. $15 \%$ of men and $5.6 \%$ of women reported having had a genital ulcer at least once; clinically confirmed ulcers were seen in $1.4 \%$ of the men and $0.8 \%$ of the women.

The objectives of the study were to inform the STD intervention trial: to explore migratory patterns of the local population that might affect STD control activities, to investigate local risk contexts and situations that might facilitate STD transmission, to explore local definitions and perceptions of STDs, and to explore people's health care seeking behaviours regarding perceived STDs.

\section{Methods}

The data of this qualitative study was gathered in 1995 by four investigators two of whom had had experience collecting data from commercial sex workers in other towns (9), and two of whom were familiar with the local languages (Kiswahili, Kisukuma, and Kizinza) and cultures. Purposeful sampling was used to select study sites that included fishers, pastoralists, farmers and traders. Among the four study sites, three were rural villages while one was a road side settlement along the highway running from Sirari (bordering 
Kenya) to Rusumo (bordering Rwanda). Interviewers stayed in the villages for over six weeks exploring peoples' perceptions about STDs and health seeking behaviour, and observing relevant events. Investigators used open-ended questions and free-listing in more than 100 informal interviews with a wide range of key informants including fishers, truck drivers, professional sex workers, STD patients, traditional healers, health care workers, bar attendants, traders, and other people of the area. Focus group discussions of 6 and 12 people were also conducted.

\section{Results}

\section{High-risk transmission sites for HIV/AIDS}

Men and women met each other at bars, guesthouses, dance contests, periodic markets, and beaches. The case for bars and guesthouses along highways and in trading centres being high transmission areas has been described (11-13).

There are also regular less automobile oriented gatherings of people. All villages had regular markets on different days of the week, referred to as "gulio", "soko" or "mnaada". These are well attended by men and women selling or buying goods and socializing. Since there is a market every day of the week somewhere in the neighbourhood, traders may spend the whole week away from home moving from one market to the other. Overnight accommodation is available. Besides providing space for sales, markets also have venues for drinking. Markets usually last for the whole day, and towards evening drinking alcohol takes over. Scenarios of drunken men and women, singing hilariously, dancing wildly and courting are common events during these occasions. Such behaviour often culminates in voluntary casual sex.

Dance performances and contests (sherehe za ngoma) occur in all the villages. Ngoma are usually colourful highspirited occasions and occur at weddings, baptisms, national holidays such as Independence Day, and local events celebrating successful harvests.

Excessive alcohol consumption (usually local brews) and overnight dancing create an environment conducive to casual sex and indeed characterize most of these occasions.

Fishermen land their catches at hundreds of beaches around Lake Victoria. Some beaches are small and isolated where only a few boats landed; others are isolated but have about 20 to 30 fishing boasts landing. Larger beaches are more integrated into the larger national and international fish market. Some fishers camp in isolated areas by themselves or with a small number of colleagues during the "dark", the 16-21 day period in which the moon is not too bright to fish. At the end of the dark they come to sell their sun-dried product at the larger beaches. Most of the fishmongers are women. As well, women sell food and drinks. Personal relationships often grow and develop out of business transactions. These relationships can be long term and some couples have children together.

\section{People at high risk}

Not all people living around "high transmission areas" are at high risk, but many are. The men at highest risk were usually those who have money and/or are away from home truckers, fishers, government officials, and businessmen.

Fishers were especially transient. Either they are on the water or temporarily camping around the lakeshore. Their movements are often determined by migration of fish and weather changes. The fishers themselves point out that their lifestyle is conducive to sex:

'Some of us are on the lake for many nights in a row. When we come back to the shore we want the soda and beer the ladies are selling. We have money to spend since we are coming with a load of fish for which the market is ready. Relationships develop. We become friends.'

Other transiting men were government and Party employees who had to travel either to Mwanza or other district towns to pick up their monthly salaries. At times this could entail staying away from home for a week, given the bureaucratic procedures involved in salary preparation. There were also those rural employees who due to the nature of their employment carrying out supervisory and support activities require travel away from home. Often these people indulge in alcohol consumption and casual sex while away.

The women most commonly available for casual or commercial sex are usually single (divorced, separated, widowed, and never married) and were mostly barmaids, petty traders, wasimbe, and secondary school students.

Barmaids as is reported in other research, working in both licensed and unlicensed bars, are employed to sell beer at low wages. To supplement their meagre income they involved themselves sexually with customers such as truck drivers who may stop overnight, and rich but promiscuous men of the area.

Petty businesswomen (wafanyabiashara wa kike) of all ethnic groups, usually ferrying whichever goods were in short supply from the border towns of Sirari and Rusumo into Mwanza and Mara Regions. They were entirely dependent on truck drivers for transport (lifti) and capital (mtaji) often on a partnership basis. Many of the truckers were their sexual partners. The businesswomen were as transient as the truck drivers. Wasimbe were divorced, separated, widowed or never married women. Many of them had children. In order to support themselves and their dependants, some engaged in petty business (selling beans, fish, tea, etc.) while others are in prostitution. Often these women end up in the company of men with money: fishermen, businessmen, truckers, miners, and government or political party employees. Some sexual relations between wasimbe and fishermen grew out of business transactions. This category of women existed in all villages and their movements were local and often limited to the neighbourhood.

There were day secondary schools, in all study villages but one, which did not have facilities to accommodate all the students. Students who do not originate from these villages have to find rented accommodation on their own. Many of 
them live with families. Others such as those attending school end up staying in guesthouses and lodgings that also accommodate customers such as miners and businessmen. Female students are often enticed into sexual relations by these "sugar daddies" who have money to feed and accommodate them.

\section{Local Nosology of Sexually Transmitted Diseases}

Free listing revealed that people in all study populations were aware of STDs and in fact had a highly developed nosology. Table 1 describes the common STDS which were reported in all villages. Both men and women were perceived to be at risk for most reported STD conditions. Some conditions were gender specific (8-10) for females and $(11,13)$ for males. Despite linguistic differences in typologies, signs and symptoms were similar in many reported STD conditions when compared to the biomedical model. In general it is possible to identify the disease of the biomedical model by lay descriptions.

Table 1: "STD" conditions characterized by perceived causes, symptomatology and biomedical diagnosis

\begin{tabular}{|c|c|c|c|}
\hline $\begin{array}{l}\text { Local terminology of } \\
\text { "STD" condition }\end{array}$ & Perceived causes & Perceived signs and symptoms & Possible medical diagnosis \\
\hline $\begin{array}{l}\text { 1. Ukimwi; Adisi; } \\
\text { Machozi ya simba; } \\
\text { Slimu; Liugonjwa }\end{array}$ & $\begin{array}{l}\text { Promiscuity; } \\
\text { witchcraft; sharing personal } \\
\text { clothes; mosquitoes }\end{array}$ & $\begin{array}{l}\text { Vomiting and diarrhoea; skin rash all over the } \\
\text { body; weight loss; confusion; hair loss; reddened } \\
\text { lips as if wearing lipstick; amenorrhea }\end{array}$ & AIDS \\
\hline $\begin{array}{l}\text { 2. Kasogone; } \\
\text { Kasogone ya damu; } \\
\text { Kasogole }\end{array}$ & $\begin{array}{l}\text { Promiscuity; } \\
\text { witchcraft; } \\
\text { sharing personal clothes }\end{array}$ & $\begin{array}{l}\text { Painless pimples around external genitalia; urine } \\
\text { with malodorous bloody pus; pain below navel; } \\
\text { genital itching; penile ulcers; dysuria. }\end{array}$ & Any STD \\
\hline $\begin{array}{l}\text { 3. Kabambaru; } \\
\text { Makabambaru; } \\
\text { Kabambale }\end{array}$ & $\begin{array}{l}\text { Promiscuity; } \\
\text { witchcraft; sharing personal } \\
\text { clothes or seat with an infected } \\
\text { person }\end{array}$ & $\begin{array}{l}\text { Boils and ulcers around the genitalia; whitish } \\
\text { malodorous pus when the boils burst; high fever; } \\
\text { pain and swelling in the groin }\end{array}$ & Chancroid; \\
\hline $\begin{array}{l}\text { 4. Kisonono; } \\
\text { Isonono; } \\
\text { Gono }\end{array}$ & $\begin{array}{l}\text { Promiscuity; } \\
\text { sharing personal clothes or seat } \\
\text { with infected person }\end{array}$ & $\begin{array}{l}\text { Urination with whitish pus-like fluid, sometimes } \\
\text { thread-like + bloody; dysuria; abdominal ache } \\
\text { sometimes; malodorous vaginal discharge. }\end{array}$ & $\begin{array}{l}\text { Gonorrhea; } \\
\text { Chlamydia; } \\
\text { Bacterial vaginosis }\end{array}$ \\
\hline $\begin{array}{l}\text { 5. Bunyoro; } \\
\text { Mabunyoro }\end{array}$ & Promiscuity & $\begin{array}{l}\text { Pimples around the external genitalia; ulcers and } \\
\text { ulcerations; dysuria; penis exfoliation }\end{array}$ & $\begin{array}{l}\text { Herpes; } \\
\text { Syphilis; Chancroid }\end{array}$ \\
\hline $\begin{aligned} \text { 6. Kichocho; } \\
\text { Kisambale }\end{aligned}$ & $\begin{array}{l}\text { Promiscuity; sharing bathing } \\
\text { places e.g. ponds }+ \text { lake sites }\end{array}$ & $\begin{array}{l}\text { Haematuria, sometimes with whitish pus; } \\
\text { abdominal noise; sporadic lesions around the } \\
\text { penis/vagina }\end{array}$ & $\begin{array}{l}\text { Urinary schistosomiasis; } \\
\text { Urinary tract infection }\end{array}$ \\
\hline $\begin{array}{l}\text { 7. Kaswende; } \\
\text { Kaswende ya damu; } \\
\text { Kaswende ya malanda }\end{array}$ & Promiscuity; genetics & $\begin{array}{l}\text { Severe pain at urination and in abdomen; } \\
\text { haematuria; pimples at the penis tip; sporadic } \\
\text { blisters and cuts at the penis foreskin }\end{array}$ & $\begin{array}{l}\text { Pyelonephritis; } \\
\text { Urinary tract infection; Urinary } \\
\text { schistosomiasis; Herpes; } \\
\text { Gonorrhoea }\end{array}$ \\
\hline $\begin{array}{l}\text { 8. Kushindwa kuzaa; } \\
\text { Mchango wa kike } \\
\text { Kwihamuenda }\end{array}$ & $\begin{array}{l}\text { Promiscuity; } \\
\text { breaking sex taboos; witchcraft; } \\
\text { genetics }\end{array}$ & $\begin{array}{l}\text { Severe pain inside the vagina and rectum during } \\
\text { menses; severe pain in lower abdomen; dysuria; } \\
\text { unusual abdominal noise }\end{array}$ & Pelvic inflammatory disease \\
\hline $\begin{array}{l}\text { 9. Ngeji; } \\
\text { Ngezi }\end{array}$ & $\begin{array}{l}\text { Promiscuity; } \\
\text { Witchcraft }\end{array}$ & $\begin{array}{l}\text { Incessant menstruation; anaemia; severe } \\
\text { abdominal pain; high fever }\end{array}$ & Menorrhagia \\
\hline 10.Kifafa cha uzazi & Breaking sex taboos & $\begin{array}{l}\text { Confusion during pregnancy, giddiness and } \\
\text { possible collapse during labour and delivery }\end{array}$ & $\begin{array}{l}\text { Toxicosis (with e.g. eclampsia) } \\
\text { in pregnancy }\end{array}$ \\
\hline $\begin{array}{l}\text { 11.Mchango wa } \\
\text { kiume; Busha; } \\
\text { Empanami }\end{array}$ & $\begin{array}{l}\text { Breaking sex taboos, i.e. sex } \\
\text { during menses }\end{array}$ & $\begin{array}{l}\text { Unusual abdominal noise; swelling in groin; } \\
\text { painful groin. }\end{array}$ & Inguinal hernia \\
\hline $\begin{array}{l}\text { 12.Bulagaza } \\
\text { Katibu Kata }\end{array}$ & Promiscuity & $\begin{array}{l}\text { Invasion of private parts by pimples; perforation } \\
\text { of private parts as condition worsens; Mutilation } \\
\text { of private parts }\end{array}$ & Cancer of the penis; Chancroid \\
\hline $\begin{array}{l}\text { 13. Uhanithi } \\
\text { Upungufu wa } \\
\text { nguvu za kiume }\end{array}$ & $\begin{array}{l}\text { Breaking sex taboos; } \\
\text { witchcraft }\end{array}$ & $\begin{array}{l}\text { Failure of a man to sustain an erection; inability } \\
\text { to perform sexual intercourse with other than } \\
\text { regular partner }\end{array}$ & Male impotence \\
\hline
\end{tabular}


Although multicausality dominated, generally, people believed that promiscuous sexual behaviours were responsible not only for the acquisition but also transmission of many disease states many of which are sexually transmitted, and some of which (e.g. schistosomiasis, hernia, toxicosis) are not. Other perceived modes of transmission included witchcraft, genetics, direct contact with personal possessions such as clothes or shared items of the infected, and violation of sex norms, taboos or trust in regular or marriage unions. Violation of sex norms and taboos entailed sex during menses, or a woman having sex with men other than her husband or regular partner while pregnant. A man is perceived as diseased if he is unable to sustain an erection, or perform sexual intercourse with other than a regular partner.

\section{Health care seeking behaviour for perceived STD conditions}

People were concerned about STDs. Once a person discovered he or she had an STD, multiple actions could be taken for those conditions perceived as treatable (table 2). Often there was no first line of treatment. Patients shopped around for services depending on their source of advice, definition of their health problems, beliefs about efficacy of treatment regimen, availability of drugs and perception of service providers. Using both the formal sector (including official STD services) and traditional healers for consultation and treatment appeared to be the norm. Some patients were undergoing modern and traditional treatment regimens simultaneously.

Table 2: Perceived STD Conditions Characterized by Health Care Seeking Behaviour

\begin{tabular}{|c|c|c|c|c|}
\hline \multirow{2}{*}{$\begin{array}{l}\text { Local terminology of } \\
\text { "STD" condition }\end{array}$} & \multicolumn{2}{|c|}{ Health care seeking behaviour } & \multicolumn{2}{|r|}{ Prevention } \\
\hline & Modern & Traditional & Modern & Traditional \\
\hline $\begin{array}{l}\text { 1. Ukimwi, Adisi } \\
\text { Machozi ya simba } \\
\text { (Tears of the lion), } \\
\text { Silimu, Liugonjwa }\end{array}$ & No treatment & No treatment & $\begin{array}{l}\text { Condoms; avoid risky } \\
\text { places + behaviours; avoid } \\
\text { cheating esp. in business }\end{array}$ & \\
\hline $\begin{array}{l}\text { 2. Kasogone, } \\
\text { Kasogone ya damu, } \\
\text { Kasogole }\end{array}$ & Injections and drugs & Nengo & $\begin{array}{l}\text { Condoms; avoid risky } \\
\text { places and behaviours }\end{array}$ & $\begin{array}{l}\text { Condoms; charcoal ashes mixed in } \\
\text { water;Tetracycline pre- and post- } \\
\text { intercourse; herb powder on penis pre- } \\
\text { intercourse; smearing pow-der in body } \\
\text { incision;charms. }\end{array}$ \\
\hline $\begin{array}{l}\text { 3. Kabambaru, } \\
\text { Makambambaru, } \\
\text { Kabambale }\end{array}$ & Injections and drugs & Nengo & $\begin{array}{l}\text { Condoms; } \\
\text { avoid risky places and } \\
\text { behaviours like prostitution }\end{array}$ & $\begin{array}{l}\text { Condoms; ashes as above; Tetracycline as } \\
\text { above; rubbing mlenda powder } \\
\text { intervaginally pre- \& post-intercourse }\end{array}$ \\
\hline $\begin{array}{l}\text { 4. Kisonono, } \\
\text { Isonono; Gono }\end{array}$ & Injections and drugs & Nengo & $\begin{array}{l}\text { Avoid risky places and } \\
\text { behaviours }\end{array}$ & $\begin{array}{l}\text { Nengo } \\
\text { Tetracycline as above }\end{array}$ \\
\hline 5. Bunyoro, Mabunyoro & Injections and drugs & Self-medication & Avoid risky behaviours & $\begin{array}{l}\text { Ashes as above; } \\
\text { Tetracycline as above }\end{array}$ \\
\hline 6. Kichocho, Kisambale & Injections and drugs & Nengo & Condoms & $\begin{array}{l}\text { Ashes as above; } \\
\text { Tetracycline as above. }\end{array}$ \\
\hline $\begin{array}{l}\text { 7. Kaswende, Kaswende ya } \\
\text { damu, Kaswende ya } \\
\text { malanda }\end{array}$ & $\begin{array}{l}\text { Injections and drugs; } \\
\text { self-medication }\end{array}$ & $\begin{array}{l}\text { Nengo; } \\
\text { Self-medication }\end{array}$ & Condoms & $\begin{array}{l}\text { Ashes as above; } \\
\text { Tetracycline as above }\end{array}$ \\
\hline $\begin{array}{l}\text { 8. Kushindwa kuzaa, } \\
\text { Mchango wa kike, } \\
\text { Kwihamuenda }\end{array}$ & & Nengo & $\begin{array}{l}\text { Condoms; avoid sex } \\
\text { during menses }\end{array}$ & $\begin{array}{l}\text { Condoms } \\
\text { Ashes as above; } \\
\text { Tetracycline as above. }\end{array}$ \\
\hline 9. Ngeji, Ngezi & & Nengo & & \\
\hline 10.Kifafa cha uzazi & & Nengo & & \\
\hline $\begin{array}{l}\text { 11.Mchango wa kiume, } \\
\text { Busha, Emphanami }\end{array}$ & Surgery & & $\begin{array}{l}\text { Condoms; avoid sex } \\
\text { during menses }\end{array}$ & $\begin{array}{l}\text { Condoms; } \\
\text { Ashes as above }\end{array}$ \\
\hline 12.Bulagaza, Katibukata & & $\begin{array}{l}\text { No cure unless } \\
\text { early treatment of } \\
\text { Mabunyoro }\end{array}$ & $\begin{array}{l}\text { Early treatment of STDs; } \\
\text { avoid multiple sexual } \\
\text { relationships }\end{array}$ & None \\
\hline $\begin{array}{l}\text { 13.Uhanithi, Upungufu } \\
\text { nguvu za kiume }\end{array}$ & & $\begin{array}{l}\text { Nengo; apologize } \\
\text { for wrong deeds }\end{array}$ & & Male Impotence \\
\hline
\end{tabular}


In some cases the line between traditional and modern medicine was blurred. For example four tetracycline tablets before intercourse and four afterwards was a method of prevention recommended by traditional healers. Formally and informally trained injectionists were found in all study villages. Both modern and traditional medical practitioners recommended condoms.

People appreciated the availability of formal health care services and were inclined to consult them. They appreciated when STD patients were not separated from the flow of other consultations, minimizing stigmatization. Injectable drugs and surgical therapies from the formal health sector were popular; injections were believed to circulate medicines in the body quickly, with immediate results on some STDs. However irregular supplies of drugs at the official health centres discouraged potential clients. They viewed drug shortages as artificial, allegedly caused by staff theft. Some health staff demanded a bribe for service that was supposed to be free. In addition there was a perceived lack of confidentiality in local health facilities. For a commercial sex workers to go to a government health facility was tantamount to a declaration of suffering before community members and service providers who knew too well their sexual behaviour. One patient summed it up:

'I know I am exposed to STDs and supposed to get treatment. But that hospital has no secrecy. If I go there all people at the hospital and in the community will know and believe that I am down with STDs even if I am suffering from other diseases. But worse still that hospital sells medicines and I have no money'.

The people in the study area strongly believed that local herbs helped prevent and cure sexually transmitted diseases. Various herbal powders were used. Drinking nengo, a decoction of herbal leaves and roots was believed to be an efficacious barrier to and cure of many kinds of infections. Divination for STD conditions perceived to be inflicted by human malevolence were performed by traditional healers. Successful normalization of the problem would also include a prescription of protective medicine such as "charms" or smearing medicines in the form of paste into body incisions.

It is not apparent why charcoal ashes mixed and taken in a glassful shortly before and after risky sexual intercourse would be effective prophylaxis. However, it is noted that British health officers suggested that Africans make a solution of wood ash and water and drink it as a way to combat influenza during the worldwide 1918-9 influenza pandemic (14).

Condoms were said to reduce pleasure and sometimes burst during sexual intercourse. It was believed that the lack of deposit of semen into women could lead to severe discomfort and pain in the spine and waist among women. Additionally, condoms conflict with obligatory reproductive roles especially in marital unions.

Direct partner notification within regular or marriage sexual relationships was firmly believed to be a strategy that would not work and could lead to severe repercussions including legal action, compensation, hatred and revenge.

\section{Discussion}

This research is part of the growing body of quantitative and qualitative literature about the people living around Lake Victoria. It corroborates what has been written about the sexual networks of truck drivers $(1,11,13,15)$, and fishers (15-17) in the Lake region. The phenomena and lifestyle of barmaids around the Lake $(11,17)$ as well as in other parts of Kenya, Uganda (17), and Tanzania $(9,12,18)$ and the vulnerability of secondary school students to sexual exploitation (19-20) has been further confirmed by these data. It has also been previously documented that while commercial sex clearly exists, not all exchange for sex for money or goods is perceived as "prostitution" (18) and can often be more genuinely understood in East Africa as "a system of favours, mutual assistance and friendliness" (2).

The data reported here is also in agreement with that of other high risk groups in Tanzania; people appreciate any delivery approach which offers effective medication (21). Injectionists have also been previously noted in Tanzania (22). A limitation of the study is that data was collected by interviewers that were medically untrained which has led to some vagueness of disease signs and symptoms especially the description of discharges, lesions, and location of pain.

This research adds new information on migration patterns, sexual networks and the specific health beliefs of the people in the rural areas near Mwanza and can be generalized to the people living in the Lake Victoria ecosystem. The migratory patterns of livelihood may be reflecting patterns that are centuries old. The people are aware of the constellations of signs and symptoms of the many STDs that afflict them. Local people knew that promiscuous sexual behaviours can lead to the unwanted consequences of pregnancy and STDs including HIV. They also believed that some diseases or conditions including HIV/AIDS, menorrhagia, toxicosis of pregnancy, and impotence were not preventable.

Some diseases associated with the genital area are not sexually transmitted. Importantly, men and women believed that kichocho or schistosomiasis is transmitted sexually and can be prevented and treated in the same way as STDS. Informants in this study described vaginal and penile micro lesions that have been documented to occur with schistosomiasis (23) but are not commonly reported in the literature. Because of these lesions, schistosomiasis has been implicated as a contributing factor to the high rates of HIV in the areas where it is most common (24). Although logical, the belief that promiscuity is responsible for schistosomiasis is incorrect, and could hamper appropriate intervention for that disease.

The data have implications beyond the specific STD intervention trial. Several interventions based on the data would be appropriate. Traditional medicine has legal backing in Tanzania since October 2002 through an act of Parliament. Research has documented that some local plants in East Africa have medicinal qualities for treating various STD conditions (25). Nengo and others may be helpful treatments that should be scientifically evaluated. 
Except for HIV/AIDS/STDS there has been poor dissemination of information about the common diseases that abound in the Region. Public education needs to be improved about general health, including schistosomiasis.

Lay thinking embraces what modern health professionals emphasize. Cooperation between traditional and western trained health practitioners would be beneficial, especially since people may be undergoing multiple treatments simultaneously. To that end, it may be desirable to encourage western-trained health providers to acquaint themselves with various local terminologies and phrases used to describe STD conditions. In addition there are nonSTD conditions such as infertility and impotence that are of concern to local people and of little health significance to western-trained health providers that could be addressed.

Western-trained health practitioners need to create userfriendly services by listening to clients, paying special attention to the socially marginalized. Many patients perceive health workers as barriers to health care because of lack of confidentiality; this has been reported elsewhere in Tanzania. ${ }^{22}$ There may be a need to incorporate increased awareness and respect for the individual patient into the education curricula of health care professionals. Discreet methods of partner notification need to be developed.

This research describes definite dynamics including migration patterns and social organization that can not be easily seen by outsiders. However the ability to respectfully tailor STD services for each group, given the characteristics of each sub-culture, needs to be explored.

Peer health educators (PHEs), appropriately chosen, equipped with knowledge of aetiology, prevention and early treatment, working in tandem with health workers may be an appropriate intervention. Sub-cultural groups can often be accessed through the PHEs, for the clinician. For example fishers who are PHEs will be better able to deliver the messages and advise at appropriate times and places. Such issues as sexual morality and trust have to surface in health education during sessions with the targeted populations and groups.

Lack of accommodation for secondary school students has been a chronic problem in Tanzania. Building safe hostels at reasonable rates for secondary school students needs to be encouraged. Students can be reached through information and education through the schools and in fact Life Skills have been started.

Barmaids have been shown in numerous studies to be paid far below the minimum wage, and yet the practice continues. Research is needed about economic and cultural attributes that may facilitate alleviation of those factors. The State could insist on implementation of minimum wage laws.

Interventions with long-term objectives should be tried. In Kenya it was found that upon the evaluation of a program that gave micro-credit to about 600 commercial sex workers, half of them exited sex work, and another one-quarter had reduced the number of clients significantly and always used condoms (26). There has been a significant increase in health status and general well being. Other such interventions accompanied by a simple research modality should be implemented in other places.

\section{Conclusion}

The existence of transient social groups with high-risk behaviour is a challenge to the organization and delivery of STD services. However there are not insurmountable differences between local interpretations of the clustering of STD signs and symptoms and biomedical diagnosis. Furthermore, prevention and treatment approaches in the modern and traditional sectors overlap and are often complementary. Approaches for effective HIV/AIDS/STD prevention and control are embedded in large processes, so must be multi-pronged, and multi-sectorial.

\section{Acknowledgements}

Thank you to Eligius Lyamuya MD, PhD for the identification of possible STDs in relation to local symptomatology.

\section{References}

1. Changalucha, J., Gavyole, A., Grosskurth, H., Hayes, R. \& Mabey, D. STD/HIV intervention and research programme Mwanza Region, NW Tanzania. Sex Trans Infect 2002; 78:91-6.

2. McMaster, D.N. (1958) Change of regional balance in the Bukoba district of Tanganyika. Tanganyika Notes and Records. 1958; 51: 79-92.

3. Hayes, R., Mosha, F., Nicoll, A. et al. A community trial of the impact of improved STD treatment on the HIV epidemic in rural Tanzania, 1. Design. AIDS 1995; 9:916-26.

1. Grosskurth, H., Mosha, F.,Todd, J. et al. A community trial of the impact of improved STD treatment on the HIV epidemic in rural Tanzania. 2. Baseline survey results. 1995; 9:927-34.

2. Munguti, K., Grosskurth, H., Newell, J., Senkoro, K., Mosha, F., Todd, J., Mayaud, P., Gavyole, A., Quigley, M. \& Hayes, R. Patterns of sexual behaviour in a rural population in north-western Tanzania. Soc Sci Med 1997; 44: 1553-61.

3. Hugonnet, S., Mosha, F., Todd, J., Mugeye, K., Klokke, A., Ndeki, L., Ross, D., Grosskurth, H. \& Hayes, R. Incidence of HIV infection in stable sexual partnerships: A retrospective cohort study of 1802 couples in Mwanza Region, Tanzania. J Acquir Immune Defic Syndr 2002; 30: 73-80.

4. Grosskurth, H, Mosha, F., Todd, J., Mwijarubi, E., Klokke, A., Senkoro, K., Mayaud, P., Changalucha, J., Nicoll, A., ka-Gina, G., et al. Impact of improved treatment of sexually transmitted disease on HIV infection in rural Tanzania: randomized controlled trial. Lancet 1995; 346: 530-6.

5. Boerma, J.T., Urassa, M., Nnko, S., Ng'weshemi, J., Isingo, R., Zaba, B. and Mwaluko, G. Sociodemographic context of the AIDS epidemic in a rural area in Tanzania with a focus on people's mobility and marriage. Sex Trans Infect 2002; 78: 97-105.

6. Outwater, A., Nkya, L., Lwihula, G., O'Connor, P., Leshabari, M., Nguma, J., Mwizarubi, B., Laukamm-Josten, U., Green, E.C. and Hassig, S. Patterns of partnership and condom use in two communities of female sex workers in Tanzania. J Assoc Nurses AIDS Care 2000; 11: 46-54.

7. Pickering, H., Okongo, M. Nnalusiba, B., Bwanika, K. and Whitworth, J. Sexual networks in Uganda: Casual and commercial sex in a trading town. AIDS CARE 1997; 9: 199-207.

8. Boerma, J.T., Urassa, M., Senkoro, K., Klokke, A. and Ng'weshemi, J.Z.L. Spread of HIV infection in a rural area of Tanzania. AIDS 1999; 13: 1233-40.

9. Laukamm-Josten, U., Mwizarubi, B.K., Outwater, A., Mwaijonga, C.L., Valadez, J.J., Nyamwaya, D., Swai, R., Saidel, T. and Nyamuryekung'e, K. Preventing HIV infection through peer education and condom promotion among truck drivers and their sexual partners in Tanzania 1990-1993. AIDS CARE 2000; 12: 27-40.

10. Gysels, M., Pool, R. and Bwanika, K. Truck drivers, middlemen and commercial sex workers: AIDS and the mediation of sex in southwest Uganda. AIDS CARE 2001; 13: 373-85.

11. Page, M.E. The Chiwaya War: Malawians and the First World War. (Colorado and Oxford: Westview Press). 2000.

12. Voeten, H., Egesah, O.B., Ondiege, M.Y., Varkevisser, C.M. and Habbema, J.D. Clients of female sex workers in Nyanza Province, Kenya: a core groups in STD/HIV transmission. Sex Trans Diseases. 2002; 29: 444-52.

13. Wilson, D.C. \& Medard, M. Programme on the Lakes of East Africa socioeconomic data set for Lake Victoria, Tanzania. Tanzania Fisheries Research Institute, Mwanza Stations/ African Studies Center, Michigan States University. 1994.

14. Pickering, H., Okongo, M., Bwanika, B, Nnalusiba, B. and Whitworth, J. Sexual behaviour in a fishing community on Lake Victoria, Uganda. Health Transition Review. 1997; 7:13-20.

15. Gysels, M., Pool, R. \& Nnalusiba, B. Women who sell sex in a Ugandan trading town" Life histories, survival strategies and risk. Soc Sci Med 2002; 54: 179-192. 
16. Mpangile, G.S., Leshabari, M.T., Kaaya, S.F. and Kihwele, D. The role of male partners in teenage-induced abortion in Dar es Salaam. African Journal of Fertility, Sexuality and Reproductive Health. 1996; 1:29-37.

17. Silberschmidt, $M$. and Rasch, $V$. Adolescent girls, illegal abortions, and "sugardaddies" in Dar es Salaam: Vulnerable victims and active social agents. Soc Sci Med 2001; 52: 1815-26.

18. Nyamuryekung'e, K., Laukamm-Josten, U., Vuylsteke, B., Mbuya, C. Hammelmann, C., Outwater, A., Steen, R., Ocheng, D., Msauka, A. and Dallabetta, G. STD services for women in truckstops in Tanzania: Evaluation of acceptable approaches. East Afr Med J 1997; 6:343-7.

19. Outwater, A., Nkya, L., Lyamuya, E., Lwihula G., Green E.C., Hogle, J., Hassig, S.E. and Dallabetta, G. Health care seeking behaviour for sexually transmitted diseases among commercial sex workers in Morogoro, Tanzania. Cult, Health Sex 2001; 3:19-33.

20. Leutscher, P., Ramarokoto, C-E., Reimert, C., Feldmeier, H., Esterre, P. and Vennervald, B.J. Community-based study of genital schistosomiasis in men from Madagascar. Lancet 2000; 355:117-8.

21. Feldmeier, H., Krantz, I. and Poggensee, G. (1994) Female genital Schistosomiasis as a risk-factor for the transmission of HIV. Int J STD AIDS 1994; 5: 368-72.

22. Kokwaru, J. Medicinal Plants of East Africa. Kampala, Nairobi, Dar es Salaam: East Africa Literature Bureau. 1976.

23. McCormick, D., Munguti, K., Ngugi, E. and Waweru, A. Finance for health: An impact assessment of Kenya voluntary women rehabilitation centre's support programmed for commercial sex workers. Abst. ThPe D5571. Durban: XIII International AIDS Conference. 2000 